\title{
Развитие российско-китайской электронной торговли
}

\section{Введение}

Согласно отчету World Internet Electronic Business Report в настоящее время только семь стран по всему миру имеют более миллиарда пользователей интернета, включая Россию, где по данным Internet World Stats к началу 2018 г. уровень проникновения в интернет достиг 76,1 \%, что создает благоприятные предпосылки для развития рынков электро-торговли. Именно на этой основе, а также в силу динамично развивающегося российско-китайского приграничного сотрудничества в последние годы данный вид экономической деятельности во многом решает проблему транспортной изоляции Дальнего Востока от центральных регионов страны. Справедливости ради следует признать негативное влияние пандемии на торговые отношения России и Китая, особенно в экспортно-импортных операциях продовольственных товаров, что, скорее всего, в ближайшее время будет преодолено.

Но даже в этих условиях привлекательность электронной торговли с Китаем для многих жителей Дальнего Востока имеет тенденцию к росту, причем по многим фракторам, включая ценовой. Таким образом, указанное направление экономического сотрудничества объективно является одним из приоритетов среднесрочной государственной политики двух стран при адекватном её научном, прежде всего, нормативно-правовом и информационном обеспечении.

Методологической основой проведенного исследования явились экономический анализ, статистико-экономический метод и опрос.

\section{Анализ литературных источников}

Несмотря на масштабное развитие электронной торговли, особенно в практике российско-китайского приграничного сотрудничества, целый ряд вопросов анализа, планирования и оценки әффективности её использования в разработке и реализации среднесрочных стратегий межстранового взаимодействия остаются малоизученными.

В экономической литературе теоретические аспекты понятия электронной торговли освещены в трудах Бергер Э. Дж., Калужского М. Л., Кубкина Ю. С., Кантаровича А. А., Балабанова И. Т., Козье Д., Холленсена С., Воробьева К. Ю., Лужецкого М. Г., Родионова А. Э., Паньшина Б. Н. и др.

В целом под электронной коммерцией ("e-commerce") понимается "осуществление бизнес-коммуникаций и трансакций в сетях и через компьютеры или как покупку/продажу товаров и услуг и передачу денежных средств при помощи цифровых коммуникаций" [3, с. 25].

Проведенное обобщение теоретических исследований позволяет определить следующие обязательные взаимосвязанные элементы успешного обеспечения этого бизнес-процесса [1, с. 17]:

1) Электронная торговля (e-trade).

2) Электронный обмен данными (Electronic Data Interchange, EDI).

(C) Трофбиенкова E.В., Юй Сунбэй, Ян Минсьь., 2021

ТРОФИМЕНКОВА Елена Викторовна, канд. экон. наук, доцент кафедры экономики и управления Владивостокского государственного университета экономики и сервиса (2. Владивосток). E-mail: trofimenkova08@mail.ru

ЮЙ СУНБЭЙ, аспирант кафедры экономики и управления Владивостокского государственного университета экономики и сервиса (2. Владивосток). E-mail: songbeiyu26317@mail.ru

ЯН МИНСЫ, аспирант кафедры экономики и управления Владивостокского государственного университета экономики и сервиса (2. Владивосток). E-mail: 531690612@qq.com 
3) Электронное движение капитала (Electronic Funds Transfer, EFS).

4) Электронные деньги (e-cash).

5) Электронный маркетинг (e-marketing).

6) Электронный банкинг (e-banking).

Следует отметить, что многие авторы употребляют перечисленные элементы как синонимы. В частности, И. Т. Балабанов и Д. Козье в своих работах не делают различий между этими понятиями $[2,7]$.

В специальном разделе "Стратегии развития торговли в Российской Федерации на период до 2025 года" под электронной торговлей понимается форма торговли, осуществляемая с использованием информационных систем, информационно-коммуникационной сети Интернет или иных коммуникационных процедур посредством электронных транзакций в сети Интернет или иных коммуникационных сетях. При этом платежи, доставка товара или оказание услуги могут осуществляться как online, так и offline. Под электронной коммерцией понимается сфера экономики, включающая все торговые и финансовые транзакции, осуществляемые при помощи компьютерных сетей [11].

В своем исследовании Б. Н. Паньшин отмечает, что электронная торговля - это эфрфективное средство продаж продукции реального сектора экономики, инструмент для выработки производственной и маркетинговой стратегии. Автоматизация цепочки поставок и работа системы в режиме реального времени позволяют значительно повысить прозрачность всего бизнеса, как для руководства предприятия, так и для клиентов [10, с. 35].

Поддерживая эту точку зрения, авторы настоящей статьи акцентируют внимание на том, что в последние годы целенаправленную политику развития электронной торговли в рамках существующей национальной стратегии увеличения масштабов и географии экспорта товаров приводит Китай. Благоприятной политико-экономической предпосылкой её успешной реализации является, с одной стороны, высокая динамика роста объемов российско-китайского торгово-экономического сотрудничества, а с другой стороны, низкий уровень самообеспеченности промышленной и продовольственной продукции регионов Дальнего Востока России, в том числе приграничных с КНР. Таким образом обеспечивается возможность реализации принципа взаимовыгодности электронной торговли для наших стран при стимулировании процессов развития инновационных трансграничный әлектронных предприятий, онлайн платформ, международных логистических систем и т.п. При этом возрастает и будет возрастать потребность в научном обосновании рациональных схем и моделей государственного регулирования электронной торговли в целях неуклонного снижения рисков для всех её участников.

\section{Оценка состояния и тенденции развития электронной торговли}

В последнее время торгово-экономическое сотрудничество между Россией и Китаем всё больше переходит от одностороннего в двустороннее, и на китайский рынок постепенно выходят российские товары.

После того, как Alibaba Group вступила на российский рынок в 2012 г., она стала сотрудничать с местными электронными платежеспособными компаниями, мобильными поставщиками, что привело к дальнейшей реализации платежей по сотовым телефонам. Кроме того, китайские производители благодаря әлектронной торговле начали активно сотрудничать с другими национальными курьерскими компаниями, не входящими в российскую почту, чтобы способствовать развитию логистики в России. Китайская и российская стороны вместе опираются на платформу трансграничных поставщиков электронной торговли, значительно снижая издержки на продажу, әффективно увеличивая эфффективность торговли, усиливая взаимовыгодное сотрудничество.

Развитие межграничной электронной торговли между Китаем и Россией резко возросло после инициативы "по пути в соседний регион", а торговое сотрудничество между двумя странами усилилось, достигнув всестороннего стратегического взаимодействия и партнерства $[8$, с. 18].

В октябре 2015 г. в г. Харбине (КНР) прошла конфреренция по обмену между региональными поставщиками электронной торговли и "интернет + торгово-экономическое сотрудничество с Россией", которая предоставляет 
Табл. 1. Лучшие онлайн-магазины рынка электронной торговли в России по объему чистых продаж в 2019 году (млн. долл. США)

\begin{tabular}{|l|c|}
\hline \multicolumn{1}{|c|}{ Онлайн-магазины } & Объем чистых продаж \\
\hline 1. wildberries.ru & 3,222 \\
\hline 2. mvideo.ru & 1,440 \\
\hline 3. ozon.ru & 0,823 \\
\hline 4. citilink.ru & 0,737 \\
\hline 5. dns-shop.ru & 0,730 \\
\hline
\end{tabular}

Источник: составлено на основе [5].

платформу для сотрудничества между Китаем и Россией в области межграничной электронной торговли.

В мае 2018 г. DHgate.com объявил о создании всестороннего сотрудничества с российской онлайн-платформой оплаты YANDEX Money, которая была широко признана своими потребителями как наиболее популярный способ оплаты в России. DHgate.com вместе с YANDEX Money предлагает более простой способ оплаты российским и дальневосточным клиентам, которые могут использовать электронные кошельки, денежные платежи, банковские переводы, кредитные карты и т.д. Таким образом, сеть DHgate.com полностью покрыла три основных российских платежных продукта: YANDEX Money, QIWI, WEBMONEY, с тем чтобы создать основу для всестороннего расширения российского рынка.

Россия стала важным рынком для трансграничной электронной торговли Китая и горячей точкой для китайских производителей электроники, расширяющих свои зарубежные предприятия.

В таблище 1 представлены самые популярные онлайн-магазины рынка электронной торговли в России по объему чистых продаж в 2019 г.

Видно, что на первом месте онлайн-магазин "Вайлдберриз", его объем чистых продаж более чем в 3 раза превышает другие интернет магазины. Его основные преимущества широкий ассортимент товаров, быстрая доставка, разная ценовая категория и возможность быстро осуществить возврат товара и денежных средств. Интернет-шопинг находится в постоянном развитии. Представленные онлайн-магазины стремятся к регулярному обновлению и усовершенствованию своих услуг, что привлекает все больше новых покупателей.

В октябре 2020 г. директор департамента развития и регулирования внешнеәкономической деятельности Минэкономразвития Л. Щур-Труханович, выступая в ходе открытой дискуссии "Трансграничная электронная торговля как драйвер развития торговых отношений ЕАЭС и Китая", которая состоялась в рамках видеофорума "Сопряжение Евразийского экономического союза и китайской инициативы "Один пояс, один путь", сказала, что "важным моментом в регулировании взаимной электронной торговли является выравнивание условий доступа товаров на китайский и российские рынки через применение одинаковых механизмов, в том числе, в части налогообложения, уплаты таможенных пошлин, доказательству соответствия товаров требованиям страны и так далее (фискальные и нефискальные меры)" [12]. Кроме того, она отметила, что создаются витрины российских производителей и ритейлеров (розничных продавцов) на глобальных китайских электронных площадках, что также будет способствовать дальнейшему росту экспорта качественных российских товаров китайским покупателям.

Проведенные авторами исследования показали, что әлектронная торговля в России начиная с 2017 г. растет примерно на $30 \%$ в год. Взрывной рост e-commerce в 2020 г. сильно изменил рынок. Безусловно на такой скачок в области электронной торговли повлияла пандемия [10]. 
Табл. 2. Объем и рост рынка электронной коммерции в 2020 г.

\begin{tabular}{|l|c|c|}
\hline \multicolumn{1}{|c|}{ Страны } & Объем рынка, млрд. долл. США & Рост рынка, \% \\
\hline 1. Китай & 955 & 5 \\
\hline 2. США & 374 & 9 \\
\hline 3. Япония & 187 & 13 \\
\hline 4. Великобритания & 133 & 19 \\
\hline 5. Южная Корея & 124 & 16 \\
\hline 6. Германия & 92 & 9 \\
\hline 7. Франция & 50 & 29 \\
\hline 8. Индия & 44 & 58 \\
\hline 9. Россия & 37 & 12 \\
\hline 10. Канада & 28 & \\
\hline
\end{tabular}

Источник: составлено на основе: [5].

По данным отчета Data Insight "Интернет-торговля в России 2020" в России в 2020 г. объем рынка электронной торговли составил 2,7 трлн. рублей, а число заказов достигло 830 млн. Данный прирост составил 78\% по отношению к уровню 2019 г. Ожидается, что к 2024 г. он вырастет еще на 34\%. При этом десктопная аудитория интернет-магазинов сократится на 25\% [9].

В 2020 г. Wildberries, Ozon, Aliexpress Russia, Яндекс.Маркет, goods.ru и другие крупные маркетплейсы стали безусловными бенефициарами пандемии. Объем этой ниши рынка вырос на 108\% до 721 млрд рублей. Всего россияне заказали с этих площадок 405 млн. товаров со средним чеком одного заказа 1780 рублей. Средний чек трансграничной торговли составляет \$10 США, основными фракторами снижения являются: онлайн-заказы превратились в повседневную практику, большая часть заказов имела бесплатную доставку, высокий рост сегментов рынка с низким средним чеком [4].

Китай и США являются мировыми лидерами рынка электронной коммерции. Россия находится на девятом месте по объему рынка ( $\$ 37$ млрд.США) и на первом - по росту рынка в десятке крупнейших е-соmmerce рынков мира (табл. 2).

Нами был проведен социологический опрос об изучении общественного мнения о развитии интернет-торговли между Китаем и Россией. Опрос проводился с помощью анкеты в индивидуальной форме, включающей открытые и закрытые вопросы. В ходе социологического исследования было опрошено 100 респондентов, среди опрошенных преобладали лица в возрасте $19-25$ лет. Из них $76 \%$ были учащиеся в учебных заведениях, а $24 \%$ - работающие. Мы выяснили, что $22,2 \%$ не пользуется услугами интернет-магазинов, а остальные $77,8 \%$ пользуются.

В рамках проведенного опроса, нами выявлены следующие преимущества торгового сотрудничества между Китаем и Россией:

- доступность всех видов перевозок. С 2018 г. посылки до 2 кг и на сумму до $\$ 10$ США на Дальний Восток, Урал и в Сибирь доставляются не через Москву, а через Владивосток;

- с 2020 г. порог беспошлинного ввоза снизился до €200 и 31 кг за одну посылку. Если посылка, заказанная в иностранном интернет-магазине, стоит дороже этой суммы, покупатель должен будет заплатить $15 \%$ от суммы превышения, но не менее €2 за кг перевеса;

- китайские интернет-магазины специализируются преимущественно по продаже дешевых товаров. 
Таким образом, интернет-торговля является одним из наиболее динамичных секторов в әкономике России. Она растет за счет числа заказов, но не за счет среднего чека, который падает третий год подряд. В настоящее время электронная торговля выходит на новый уровень развития между странами, не смотря на политические и экономические границы.

\section{Заключение}

Россия уже является одним из крупнейших экспортеров әлектронной торговли в Китае, и российские интернет-пользователи очень любят китайские товары. В настоящее время предпринимаются активные усилия по совместным усилиям по продвижению развития трансграничных электро-предприятий, значительно увеличивая әффективность торговли.

Проведенные исследования, в том числе по развитию электронной торговли на Дальнем Востоке с КНР за последние 5 лет, показывают, что до настоящего времени как в научном, так и в практическом обеспечении этого бизнес-процесса существует много нерешенных проблем. Это недоверие покупателей в силу отсутствия инфраструктурного обеспечения, существующих рисков невозврата денежных средств, время доставки до пункта назначения, снижение доли налоговых отчислений в пользу государства, уменьшение объема розничной торговли. На устранение этих и других проблем должны быть направлены меры государственного регулирования торгово-экономических отношений России и Китая.

\section{Литература}

1. Астахова Е.В., Абасова Ю.Н. Влияние электронной коммерции на развитие международного делового сотрудничества предприятий Приморского края // АНИ: экономика и управление. 2017. Т. 6. № 1(18). С. 17-21.

2. Балабанов И.Т. Электронная коммерция. СПб.: Питер, 2002. 335 с.

3. Бергер Э.Дж. Е-коммерция и цепи поставок: ломка прежних границ / Управление цепями поставок. Под ред. Дж.Л. Гатторны. М.: Индра-М, 2008. 670 с.

4. Интернет-торговля в России 2020 // Performance360, [Электронный ресурс]. URL: https://performance360.ru/e-commerce-russia-2020-data-insight-2020/ (дата обращения: 25.08.2021).

5. Исследовательское агентство в России, [Электронный ресурc]. URL: https:// datainsight.ru/ (дата обращения: 25.08.2021).

6. Калужский М.Л. Электронная коммерция: маркетинговые сети и инфраструктура рынка. М.: Экономика, 2014. 328 с.

7. Козье Д. Электронная коммерция: пер. с англ. М.: ИТД "Русская Редакция", 1999. $288 \mathrm{c}$.

8. Линлин Сонг. Анализ комплексного развития цифровой экономики с помощью трансграничной электронной торговли провинщии Хэйлунцзян с Россией // Власть и управление на Востоке России. 2020. № 4 (93). С. 16-23.

9. Онлайн набрал обороты // Российская газета. Неделя № 260(8314), [Электронный pecypc]. URL: https://rg.ru/2020/11/18/elektronnaia-torgovlia-v-rossii-k-2024-godudostignet-72-trln-rublej.html (дата обращения: 20.08.2021).

10. Паньшин Б.Н. Электронная торговля: теория и практика: курс лекций. Минск: БГУ, 2009. 217 с.

11. Стратегии развития торговли в Российской Федерации на период до 2025 года // Минпромторг России, [Электронный ресурс]. URL: https://minpromtorg.gov.ru/docs/ (дата обращения: 20.08.2021).

12. Трансграничная электронная торговля как драйвер развития торговых отношений ЕАЭС и Китая // Министерства экономического развития РФ, [Электронный pecypc]. URL: https://economy.gov.ru/material/news/v_mer_predlozhili_kitayu_obsudit_ razvitie_elektronnoy_torgovli_vysokokachestvennymi_tovarami_iz_rf.html (дата обращения: 23.08.2021). 


\section{Транслитерация по ГОСТ 7.79-2000 Система Б}

1. Astakhova E.V., Abasova YU.N. Vliyanie ehlektronnoj kommertsii na razvitie mezhdunarodnogo delovogo sotrudnichestva predpriyatij Primorskogo kraya // ANI: ehkonomika i upravlenie. 2017. T. 6. № 1(18). S. 17-21.

2. Balabanov I.T. EHlektronnaya kommertsiya. SPb.: Piter, 2002. $335 \mathrm{~s}$.

3. Berger EH.Dzh. E-kommertsiya i tsepi postavok: lomka prezhnikh granits / Upravlenie tsepyami postavok. Pod red. Dzh.L. Gattorny. M.: Infra-M, 2008. 670 s.

4. Internet-torgovlya v Rossii 2020 // Performance360, [EHlektronnyj resurs]. URL: https://performance360.ru/e-commerce-russia-2020-data-insight-2020/ (data obrashheniya: 25.08 .2021 .

5. Issledovatel'skoe agentstvo v Rossii, [EHlektronnyj resurs]. URL: https://datainsight.ru/ (data obrashheniya: 25.08.2021).

6. Kaluzhskij M.L. EHlektronnaya kommertsiya: marketingovye seti i infrastruktura rynka. M.: EHkonomika, 2014. 328 s.

7. Koz'e D. EHlektronnaya kommertsiya: per. s angl. M.: ITD "Russkaya Redaktsiya", 1999. $288 \mathrm{~s}$.

8. Linlin Song. Analiz kompleksnogo razvitiya tsifrovoj ehkonomiki s pomoshh'yu transgranichnoj ehlektronnoj torgovli provintsii KHehjluntszyan s Rossiej // Vlast' i upravlenie na Vostoke Rossii. 2020. № 4 (93). S. 16-23.

9. Onlajn nabral oboroty // Rossijskaya gazeta. Nedelya № 260(8314), [EHlektronnyj resurs]. URL: https://rg.ru/2020/11/18/elektronnaia-torgovlia-v-rossii-k-2024-godu-dostignet-72-trln-rublej.html (data obrashheniya: 20.08.2021).

10. Pan'shin B.N. EHlektronnaya torgovlya: teoriya i praktika: kurs lektsij. Minsk: BGU, 2009. $217 \mathrm{~s}$.

11. Strategii razvitiya torgovli v Rossijskoj Federatsii na period do 2025 goda // Minpromtorg Rossii, [EHlektronnyj resurs]. URL: https://minpromtorg.gov.ru/docs/ (data obrashheniya: 20.08.2021).

12. Transgranichnaya ehlektronnaya torgovlya kak drajver razvitiya torgovykh otnoshenij EAEHS i Kitaya // Ministerstva ehkonomicheskogo razvitiya RF, [EHlektronnyj resurs]. URL: https://economy.gov.ru/material/news/v_mer_predlozhili_kitayu_obsudit razvitie_elektronnoy_torgovli_vysokokachestvennymi_tovarami_iz_rf.html (data obrashheniya: 23.08 .2021$)$. 
Трофименкова Е.В., Юй Сунбэй, Ян Минсы. Развитие российско-китайской электронной торговли.

Одним из перспективных направлений цифровизации российско-китайского торгово-экономического сотрудничества является развитие электронной торговли. В статье на основе обобщения литературных источников и анализа практики последних лет сделан вывод о растущей привлекательности этого инновационного вида предпринимательства для удалённых от центра страны приграничных с КНР регионов Дальнего Востока. Сделанная оценка состояния и тенденций электронной торговли выявила позитивную динамику её развития в России начиная с 2017 года при достижении объема рынка в 2,7 трлн. руб. в 2020 году. Авторами на основе проведённого социологического опроса определены основные преимущества электронной торговли и существующие проблемы для их учёта в государственном регулировании торговоэкономических отношений России и Китая.

Ключевые слова: торгово-экономическое сотрудничество, электронная торговля, Китай, российский Дальний Восток, динамика, оценка, государственное регулирование

Trofimenkova E. V., Yuj Sunbehj, Yan Minsy. Development of Russian-Chinese e-commerce.

One of the promising areas of digitalization of Russian-Chinese trade and economic cooperation is the development of electronic commerce. In the article, based on a generalization of literary sources and an analysis of the practice of recent years, it is concluded that this innovative type of entrepreneurship is becoming increasingly attractive for the Far East regions bordering the PRC far from the center of the country. The assessment of the state and trends of e-commerce revealed the positive dynamics of its development in Russia since 2017, when the market volume reached 2.7 trillion. rub. in 2020. The authors, on the basis of a sociological survey, identified the main advantages of e-commerce and the existing problems for taking them into account in the state regulation of trade and economic relations between Russia and China.

Key words: trade and economic cooperation, e-commerce, China, the Russian Far East, dynamics, assessment, government regulation

Для цитирования: Трофименкова Е.В., Юй Сунбэй, Ян Минсы. Развитие российско-китайской электронной торговли // Ойкумена. Регионоведческие исследования. 2021. № 4. C. 49-55. DOI: 10.24866/1998-6785/2021-4/49-55

For citation: Trofimenkova E. V., Yuj Sunbehj, Yan Minsy. Development of Russian-Chinese e-commerce // Ojkumena. Regional researches. 2021. № 4. P. 49-55. DOI: 10.24866/1998$6785 / 2021-4 / 49-55$ 